\title{
Néstor Perlongher y sus cadáveres: del neobarroso a la necropoética
}

Néstor Perlongher and his corpses: from the 'neobarroso' to necropoetics

Néstor Perlongher e os seus cadáveres: do neobarroso à necropoética

\section{Ezequiel Zaidenwerg}

NEW YORK UNIVERSITY, ESTADOS UNIDOS

Candidato doctoral, Departamento de Español y Portugués, New York University. Magíster en escritura creativa, área poesía, New York

University. Es autor de los poemarios Doxa (Vox, 2007), La lírica está muerta (Vox, 2011). Correo electrónico: ez48o@nyu.edu

Artículo de reflexión

Documento accesible en línea desde la siguiente dirección: http://revistas.javeriana.edu.co doi: 10.11144/Javeriana.cl19-38.npsc 


\section{Resumen}

Este artículo explora la política de la forma poética en la obra de Néstor Perlongher en el contexto de la última dictadura militar argentina. En primer lugar, se analizan las operaciones de apropiación y adaptación que el poeta, antropólogo y militante argentino realiza sobre el neobarroco cubano de Lezama y Sarduy, a la hora de implantar en el Río de la Plata una poética que Perlongher llamaría "neobarrosa". Luego se estudia la fascinación de Perlongher por los cadáveres nacionales, desde Eva Perón hasta los desaparecidos, y se postula que frente a la opción militante, el argentino se inclina por una necropoética. Así, formas y tradiciones dadas por muertas se levantan como zombis, y en ese énfasis en la corporeidad del lenguaje, Perlongher no sólo pone el cuerpo políticamente sino que les devuelve materialidad a los cuerpos borrados de los desaparecidos.

\section{Palabras clave: Poesía} latinoamericana; poesía argentina; Perlongher; forma; política; neobarroco; neobarroso; cadáveres; zombis; dictadura; biopolítica; necropoética

\section{Abstract}

This article explores the politics of the poetic form in the works of Nestor Perlongher, in the context of the last military dictatorship in Argentina. First of all, we analyze the appropriation and adaptation operations that the Argentinian poet, anthropologist, and militant performed on the Cuban neo-baroque of Lezama and Sarduy when it comes to imposing in Rio de la Plata a poetics that Perlongher would call "neobarrosa". Then, we study the fascination of Perlongher with national corpses, from Eva Peron to the disappeared, and postulate that, faced with the militant option, the Argentinian inclines for necropoetics. In this way, forms and traditions that were left for dead raise as zombies and, in this emphasis on the corporality of language, Perlongher not only gives them a political body, but returns the material quality to the faded bodies of the disappeared.

Keywords: Latin American poetry; Argentinian poetry; Perlongher; form; politics; neo-baroque; neobarroso; corpses; zombies; dictatorship; biopolitics; necropoetics

\section{Resumo}

Este artigo explora a política da forma poética na obra de Néstor Perlongher no contexto da última ditadura militar argentina. Em primeiro lugar, analisam-se as operações de apropriação e adaptação que o poeta, antropólogo e militante argentino realiza sobre o neobarroco cubano de Lezama e Sarduy, na hora de implantar no Río de la Plata uma poética que Perlongher chamaria de "neobarrosa". Após, estuda a fascinação de Perlongher pelos cadáveres nacionais desde Eva Perón até os desaparecidos, e postula-se que frente à opção militante, $o$ argentino prefere uma necropoética. Assim, formas e tradições dadas por mortas levantam-se como zombies e, nessa ênfase na corporeidade da linguagem, Perlongher não apenas põe o corpo politicamente senão que devolve sua materialidade aos corpos borrados dos desaparecidos.

Palavas-clave: Poesia latinoamericana; poesía argentina; Perlongher; forma; política; neobarroco; neobarroso; cadáveres; zombies; ditadura; biopolitica; necropoética

\section{Cómo citar este artículo:}

Zaidenwerg, Ezequiel. "Néstor Perlongher y sus cadáveres: del neobarroso a la necropoética". Cuadernos de Literatura 19.38 (2015): 432-449. http://dx.doi.org/10.11144/Javeriana.cl19-38.npsc 


\section{Forma, artificio y política}

Trotskista, militante por los derechos de los homosexuales, antropólogo y autor de importantes estudios sobre la pandemia del SIDA y la prostitución masculina en Brasil, Néstor Perlongher fue el escritor más politizado y más político de su generación. Sin embargo, su poética elude radicalmente tanto el arte comprometido, típico de la poesía de los años sesenta, como la aprehensión irónica del Zeitgeist que caracterizaría a la generación posterior, la de los años noventa. La suya es una opción por el barroco que, si bien adhiere programáticamente al neobarroco cubano de Lezama y Sarduy para extenderlo al cono sur, encuentra diferencias fundamentales con ese movimiento transcontinental.

La política literaria de Perlongher recupera esa opción por la forma y el artificio de sus predecesores cubanos y, como en la producción de aquellos, la voluptuosidad formal y el regodeo en la corporeidad del lenguaje erotizan y politizan la escritura. Como observa Cecilia Palmeiro:

La producción escrita de Perlongher convoca a una serie de géneros a entrecruzarse, a contaminarse y a suspender las jerarquías institucionales en nombre de una experiencia extrema: la de la exploración del deseo homoerótico masculino como un modo de fuga de la subjetividad canónica. Y en el centro de su producción, no se trata de hablar del cuerpo, sino de poner el cuerpo (para la política, para la literatura, para la antropología). Toda su producción puede ser pensada como una poética y una política del cuerpo desterritorializado por un deseo que puede ser "una pasión de abolición" que se alza contra toda institucionalización identitaria, jerarquizante y ordenadora, y una ética de la sensualidad dionisíaca $(9-10)^{1}$.

Amén de señalar el activismo de Perlongher, Palmeiro pone el foco sobre un aspecto central de su producción: al describirla como una "política y poética del cuerpo desterritorializado", hace hincapié en el hecho fundamental de que ambos polos están ligados de manera indisociable, al punto de que es imposible entenderlos por separado. Según Palmeiro, esa confluencia de política y poética se localiza en el cuerpo. Pero la crítica argentina va más allá: "no se trata de hablar del cuerpo, sino de poner el cuerpo" (167).

En efecto, el cuerpo no es sólo un tema recurrente en los poemas de Perlongher. Más que su tematización a nivel del contenido, lo fundamental es el carácter performático y performativo de ese "poner el cuerpo", el modo en

1 Palmeiro, Cecilia, "Locas, milicos y fusiles: Néstor Perlongher y la última dictadura argentina", Estudios 19:38 (-julio-diciembre de 2011): 9-10. 
que ese gesto se traslada a la forma y a la materialidad del lenguaje poético, él mismo entendido como una corporeidad. Ahora bien, se trata de precisar la naturaleza de ese cuerpo del que, según Palmeiro, no es necesario hablar, sino más que nada, poner. Y, asimismo, de dirimir dónde -y cómo- hay que ponerlo, incluso cuando falta: precisamente de esto nos hablará "Cadáveres", su célebre poema sobre los cuerpos de la dictadura. Por eso, en primer lugar es necesario precisar los alcances de esa concepción corporal de la lengua poética, y para ello se impone precisar la peculiar lectura de Perlongher del barroco y, fundamentalmente, del neobarroco.

En 1991, Perlongher preparó una antología llamada Caribe Transplatino. Poesía neobarroca cubana e rioplatense ${ }^{2}$, publicada en portugués por la editorial Illuminiras de San Pablo. Un ensayo del propio Perlongher encabezaba la muestra a manera de introducción. Desde el primer párrafo Perlongher se refiere a la potencia a la vez destructora y generativa del lenguaje poético neobarroco:

$[\mathrm{L}] \mathrm{a}$ "lepra creadora" lezamesca mina o corroe -minoritariamente más eficazmente- los estilos oficiales del buen decir. Es precisamente la poesía de José Lezama Lima, que culmina en su novela Paradiso, la que desata la resurrección, primeramente cubana, del barroco en estas landas bárbaras. ("Neobarroco y neobarroso" 19) $)^{3}$

La idea de una "resurrección" del barroco parece implicar de manera necesaria su muerte. De hecho, en el siguiente párrafo Perlongher dice que éste había sido "dado como muerto y enterrado en el siglo XIX". Eso se liga con una concepción general de la lengua poética. Desde la latinidad clásica, la lírica representó su propio mito de origen a partir de su muerte. Así, en las Metamorfosis de Ovidio, Orfeo, el poeta por excelencia de la mitología grecolatina, tras desdeñar los requiebros amorosos de las Ménades, es brutalmente asesinado y despedazado por éstas. La cabeza y la lira van a dar al río Hebro, donde siguen cantando aun después de la muerte:

Membra iacent diversa locis. Caput, Hebre, lyramque excipis, et (mirum!) medio dum labitur amne,

2 Esta introducción sería reeditada en numerosas ocasiones, hasta convertirse en uno de los prólogos de Medusario (México D.F., Fondo de Cultura Económica, 1996), probablemente la antología definitiva de esa "tendencia neobarroca" en la poesía latinoamericana.

3 Perlongher, Néstor, "Neobarroco y neobarroso", en Medusario (19) 
flebile nescio quid queritur lyra, flebile lingua murmurat exanimis, respondent flebile ripae ${ }^{4}$.

Como se ve en Ovidio, desde la época clásica la poesía representa su propio mito de origen a partir de su muerte, que sin embargo no funciona como una instancia de cancelación sino como una de productividad. La lírica está muerta desde siempre pero vive en y de su muerte: es un undead, un no-muerto, un cuerpo fragmentado al borde de la desaparición de cuyos restos, sin embargo, surge una voz que canta.

Por lo demás, en los versos de Ovidio se esconde otra clave: la afirmación de su carácter formal. La técnica también está condenada desde el inicio a la obsolescencia pero es incapaz de morir, en tanto imperativo formal. De allí que en la representación de Ovidio, estos restos de Orfeo -no sólo en la acepción cadavérica de la palabra, sino también como exceso o suplemento productivono sean sólo su cabeza, en tanto vehículo de su voz, sino también la lira. Ese instrumento fantasmal, aun escindido del cuerpo, es incapaz de separarse de él y sigue entonando sus quejas, a la espera de otra mano que la pulse para arrancarle nuevas melodías.

Pero volvamos a Perlongher para señalar cómo, desde el inicio, a la hora de cartografiar sus filiaciones, elige una declaración metapoética de Lezama ligada a la muerte y a la descomposición, pero fundamentalmente a la fragmentación del cuerpo (la "lepra creadora"), a la vez que delimita el ámbito de acción ese oxímoron y lo vincula a la política: "Es en el plano de la forma que el barroco, y ahora el neobarroco, atacan" (Perlongher 20).

Como notaba Palmeiro, política y poética son inseparables para Perlongher. Y no se trata de una política de resistencia pasiva ni de pacífica asimilación sino un ataque a través de la forma. A raíz de esto, en una entrevista, Luis Chitarroni le pregunta a Perlongher por las relaciones y los puntos de contacto con el barroco español. Tras deslindarse de intentos de decodificación como los de Dámaso Alonso, Perlongher afirma: "La otra manera es dejarse llevar por esos flujos, que es lo que hice con Lezama: me zambullí en él. Entonces lo que aparece es una especie de máquina, un uso bélico del barroco aúreo" (Chatarroni 23-24).

4 Ov. Met. 11, 50-54. En mi traducción: "Los miembros yacen en diversos sitios. / A ti te toca recibir la lira / y la cabeza, Hebro, y ¡oh milagro!, / por el medio del cauce van flotando. / La lira, lacrimosa, se lamenta / no sé de qué y, exánime, la lengua / murmura lacrimosa, y las orillas / responden, lacrimosas, sus lamentos". 
En las palabras de Perlongher resuena inequívocamente la terminología de Gilles Deleuze y Félix Guattari, sus teóricos de cabecera. En su prólogo a Caribe Transplatino vuelve a referirse al barroco como máquina de guerra: "La máquina barroca no procede, como Dadá, a una pura destrucción. El arrasamiento no desterritorializa en el sentido de tornar liso el territorio que invade, sino que lo baliza de arabescos y banderolas clavadas en los cuernos del toro europeo"(Perlongher 24). El ataque de la máquina barroca no tiene como fin la mera destrucción de la institución "arte", típica del programa de las vanguardias, sino que, como decía Perlongher, funciona a nivel formal por proliferación y saturación del significante. El mismo Perlongher señala la anomalía de esta política de la forma en el contexto político general: "Es sorprendente - nota el crítico cubano González Echevarría-, que justamente 'el único país del hemisferio que experimenta una revolución política de gran alcance, sea el que produce una literatura que, desde cualquier perspectiva comúnmente aceptada, se aleja de lo que se concibe como literatura revolucionaria" (24).

Este desajuste entre literatura y Zeitgeist se condice plenamente con la política literaria de Perlongher, salvo que en el caso cubano esta opción por la forma tiene lugar en el contexto de una revolución marxista, y en el argentino se produce bajo un régimen militar de derecha que se legitima como contrarrevolucionario. Sin embargo, Perlongher comparte con los cubanos la experiencia del exilio ante el autoritarismo estatal: interior en Lezama, a quien el régimen le negó la visa de salida; europeo en Sarduy, que se radicó en París; y brasileño en Perlongher.

Luego de desarrollar su concepción del barroco y de señalar las diferencias entre éste y el neobarroco de Lezama y Sarduy, Perlongher se adentra en el meollo de su argumentación: los orígenes y características del neobarroso, su peculiar adaptación del neobarroco. Resulta sumamente interesante la genealogía neobarrosa que construye Perlongher por lo disímil de los elementos que la constituyen pero también por las relaciones, a veces impensadas, que establece entre ellos. Y en el gesto de publicar su ensayo por primera vez en Brasil, con una muestra de poemas traducidos al portugués, hay además un guiño a la vanguardia brasileña: al concretismo de Haroldo de Campos, cuya influencia declara, pero también, en ese afán omnívoro de incorporación y mezcla, a la antropofagia de Oswald de Andrade.

Específicamente, la biblioteca de precursores que configura Perlongher está constituida, en primer lugar, por los modernistas, que curiosamente aparecen ligados al surrealismo:

Ya Darío lo había artificializado todo, y algún Lugones lo seguiría en el paciente engarce de las jaspeadas rimas. Por otro lado, el neobarroco parece resultarpuede arriesgarse- del encuentro entre ese flujo barroco que es, a pesar de sus 
silencios, una constante en el español, y la explosión del surrealismo. Alguna vez habría que reconstruir (...) los despliegues del surrealismo en su implantación latinoamericana, cómo sirvió en esas costas bravías para radicalizar la empresa de desrealizacón de los estilos oficiales -el realismo y sus derivaciones, como la "poesía social". (...) En el propio Lezama se siente el impacto del surrealismo, sobre el cual se monta o labra la construcción barroca. (Perlongher 31-35)

A continuación, Perlongher cita otro antecedente: En la masmédula, de Oliverio Girondo. Lo interesante es que, si bien se trata de un libro fuertemente experimental, en tanto el énfasis está puesto en la materialidad del significante, a nivel prosódico Girondo se ajusta perfectamente a la gran tradición métrica castellana. Martín Prieto fue el primero en observar que, lejos del libertinaje versolibrista, había en Girondo una voluntad de apropiación, descomposición y recomposición de esquemas tradicionales: "El enorme trabajo de descomposición rítmica, hecho a partir del heptasílabo, que es un hemistiquio del alejandrino, uno de los metros clave del modernismo, convierte a En la masmédula en una Perd especulación teórica sobre el programa modernista" (33).

Es cierto que en Girondo hay un trabajo insistente con el heptasílabo. Sin embargo, Prieto hace una lectura parcial: si se estudia en mayor detalle la métrica de En la masmédula, se observará que, además de la profusión de heptasílabos, hay una recurrencia casi igualmente considerable de endecasílabos que, dicho sea de paso, son el metro preferido de Perlongher: "[Y]o tengo un problema con la escansión: no puedo salir de las cosas poéticas, de la cosa tipo endecasílabo... la necesito. Se me pega la musiquita" (Chitarroni 23).

Sin embargo, lejos de desautorizar la hipótesis de Prieto, esto la lleva aún más lejos: además de una deconstrucción formal del modernismo, a través de la separación de los hemistiquios heptasilábicos del alejandrino, hay una apropiación crítica de la silva, una libre combinación de endecasílabos y heptasílabos que, en su variante rimada, popularizará Góngora en su obra más conocida y radical, las "Soledades".

Precisamente, más que el barroco en general, las "Soledades" son el modelo poético de los neobarrocos. Por consiguiente hay, en cierta medida, un desplazamiento metonímico - muy apropiado, por cierto- en la elección del nombre. Sin duda, habría sido más ajustado llamar al movimiento neogongorismo, puesto que la aventura que emprende el poeta cordobés con el lenguaje va mucho más allá de las florituras y los juegos conceptuales de sus contemporáneos. La revolución gongorina -no le cabe otro mote- lleva a cabo un triple movimiento, impensable en el siglo XVII pero ciertamente más afín con la experiencia del XX. 
En primer lugar, Góngora tensa al máximo la unidad del sentido: es cierto, como reconocen los neobarrocos, que las "Soledades" pueden ser decodificadas como una ecuación matemática y que, por consiguiente, hay un significado último. Pero, salvo que uno sea Dámaso Alonso o Robert Jammes, en la experiencia de la lectura, el significado comunicacional del poema permanece siempre esquivo, como una asíntota, algo que ven muy bien los neobarrocos. En segundo lugar, Góngora lleva al límite dos unidades de las que la poesía tardaría unos doscientos cincuenta años más en comenzar a desembarazarse: la estrofa y la rima. Si bien la silva es una forma estrófica rimada, la absoluta libertad para construir las estrofas y establecer las rimas, que a veces se alejan tanto que el oído ya no las percibe, lleva a ambas categorías a un umbral de desaparición. Finalmente, el tercer movimiento consiste en la apropiación de la sintaxis, y muy a menudo del léxico ${ }^{5}$, del latín, para implantarlos como un cuerpo extraño en el castellano. Este gesto tiene, a su vez, una doble relevancia. Primero, porque socava el sitial de privilegio del latín como lengua culta de las élites letradas. Y segundo, porque al insertar una lengua (no-)muerta en el cuerpo del castellano, se lleva a cabo un gesto que podría definirse como biopoético. En efecto, el latín, lengua muerta para la comunicación diaria pero undead en tanto certifica la pertenencia y el acceso a la cultura letrada, al fundirse con el castellano arrastra a ambas lenguas a una entrevida donde la función comunicativa del lenguaje parece siempre a punto de expirar, y donde un cuerpo nuevo, en su pura materialidad, es creado a partir de esa muerte. Además, en ese doble movimiento de muerte e inhumación (del lenguaje comunicativo) y de resurrección y exhumación (de esa "lengua muerta"), hay una potencia que, al poner en sincronía distintas temporalidades, perturba la organización geológica de la historia de la cultura, removiendo las diversas capas de sedimentos y fósiles, para producir un efecto de dislocación del presente. De esto, precisamente, se trata el neobarroso, sobre el que volveremos al final de esta sección.

Volviendo al experimento de Girondo, gongorino también, Tamara Kamenszain cita en el epílogo de Medusario unos versos de "Cansancio", último poema de En la masmédula: "Y de los intimísimos remimos y recaricias de la lengua y de sus regastados páramos y reconjunciones y recópulas y sus remuertas reglas y necrópolis y reputrefactas palabras, simplemente cansado del cansacio" (349).

5 En una lectura contemporánea, los préstamos lexicales del latín son menos visibles, porque muchos se han aceptado y pasado a la lengua corriente. Sin embargo, basta con leer un texto como "La culta latiniparla o la aguja de navegar cultos", del gran rival de Góngora, Francisco de Quevedo y Villegas, para comprender cuán extraños sonaban al oído castellano estos neologismos de origen latino. 
Afirma Kamenszain: “CCómo escribir poesía, entonces, después de En la masmédula, si el cansancio es realmente una enfermedad contagiosa? (...) Girondo venía escapando de la rima lugoniana pero, sobre todo, de esa actitud autoral sumisa que da por descontada la naturalidad del recurso (...) La finalidad es inyectarle a las 'remuertas' un plus, una especie de autovacuna" (487-488). La mención de la "enfermedad contagiosa" recuerda la "lepra creadora" de Lezama, y decididamente contribuye a cimentar una visión clínico-forense de la poesía. Pero lo crucial aquí es la idea de que, al inyectarle al cuerpo muerto de la lírica ("las remuertas") una "autovacuna", el resultado es un "plus" productivo. A este respecto, podrían ser útiles las reflexiones de Roberto Esposito sobre inmunidad, autoinmunidad y biopolítica (Esposito 101-114), para extenderlas al ámbito de la poética. Para el teórico italiano, la inmunización llevada al extremo, acaba destruyendo la vida que debía proteger, como en el caso de las enfermedades autoinmunes. Pero si aceptamos que la lírica está muerta desde el origen, la autoinmunidad deviene una forma de salud, de preservar la productividad de ese estado de muerte permanente. Y, precisamente, en el caso de Perlongher, sobre todo para aproximarse a "Cadáveres", que responde a la tanatopolítica del Proceso, no huelga una lectura que contemple tanto la dimensión biopolítica de la poética como la dimensión poética de la biopolítica.

Efectivamente, tanto el gongorismo como el modernismo y la poesía de Stéphane Mallarmé -también mencionada por Perlongher, siguiendo a Echava$\operatorname{rren}^{6}$, como antecedente de aquello que hay de las vanguardias en el neobarroco-, tienen un fuerte componente autoinmune, entendido en términos de esa autoinoculación de la que hablaba Kamenszain. Al cuerpo moribundo de una estética dominante se le inyecta una cepa perversa de sí mismo, una "lepra creadora" que la exaspera y, tras llevarla a su límite, arroja como resultado un cuerpo nuevo, medio vivo y medio muerto, pero productivo.

En el caso de Mallarmé, el autor va intensificando el trabajo formal hasta llevarlo al paroxismo (el ejemplo típico es su "Sonnet en ix", con sus rimas imposibles). Esto sólo puede llevar a una destrucción creadora: "Un coup de dés", que es uno de los antecedentes fundamentales de las vanguardias occidentales,

6 En su lúcido prólogo a Medusario, Roberto Echavarren distingue dos tradiciones en la poesía latinoamericana: una ligada al compromiso, cuyo paladín sería Neruda, y otra que bautiza "poesía del significante", en la segunda línea se ubicarían, por supuesto, los neobarrocos. Echavarren agrega a los concretistas brasileños, que Perlongher sólo había nombrado al pasar. Para una discusión sobre la importancia de la dimensión formal del concretismo para el neobarroco, vid. Porrúa, Ana, "Cosas que se están hablando: versiones sobre el neobarroco", BOLETIN 13/14 del Centro de Estudios de Teoría y Crítica Literaria (Diciembre 2007 - Abril 2008). 
al romper con la ligazón, hasta el momento indisoluble, entre la poesía y el oído, para enfatizar la dimensión visual. Góngora, mediante el movimiento ya descrito, vuelve el barroco -que aún guardaba la herencia petrarquista- contra sí mismo, extremando sus procedimientos para estallarlo en todos los niveles. Y si bien ya hay autoparodia en Rubén Darío, se observa mejor en la segunda oleada de modernistas un uso doblemente artificioso, desnaturalizado, de la amanerada retórica dariana. La poesía, al mirarse a sí misma reflejada en las aguas incómodas de su propia tradición, se convierte en un cisne cuyo cuello hay que torcer, como en el poema del mexicano Enrique González Martínez ${ }^{7}$, precisamente porque en su muerte se cifra su supervivencia. $\mathrm{O}$, en términos más propiamente formales, esto se ve en el pasaje entre "Los heraldos negros" (1918) y "Trilce" (1922), de César Vallejo, autor ineludible para todo aquel que pretenda escribir poesía en América Latina. Varios de los poemas de "Trilce", que se caracteriza por su experimentalismo, eran en sus primeras versiones perfectos sonetos modernistas, afines a la estética más ligada a ese movimiento de "Los heraldos negros", que Vallejo desfiguró para incluir en su libro más famoso, pero no al punto de que se deje de percibir la forma original: son, podría decirse, sonetos zombis.

Pero veremos que también hay algo del orden de la autoinmunidad en la apropiación que hace Perlongher del neobarroco. Para terminar su ensayo, el poeta vuelve a uno de los textos fundacionales de esta tendencia, "El barroco y el neobarroco", publicado en 1972 por Severo Sarduy. En este ensayo fundamental, el cubano ofrecía una definición ambigua de lo barroco. Por un lado, a partir de su etimología, lo asociaba a lo inorgánico: "Fue la gruesa piedra irregular -en español barrueco o berrueco, en portugués barroco-, la roca, lo nudoso, la densidad aglutinada de la piedra -barrueco o berrueco-" (188). Por el otro lado, por desplazamiento del significante, se lo ligaba a lo orgánico: "Nódulo geológico, construcción móvil y fangosa, de barro, pauta de la deducción o perla, de esa aglutinación, de esa proliferación incontrolada de significantes" (187).

A continuación, Sarduy contrasta dos versiones del barroco: "Si en su mejor gramática en español -la obra de Eugenio d'Ors-, tratamos de precisar el concepto de barroco, veremos que una noción sustenta, explícita o no, todas las definiciones, fundamenta todas las tesis: es la del barroco en tanto que retorno a lo primigenio, en tanto que naturaleza"(180). A este barroco como vuelta a la naturaleza, Sarduy le opone una concepción ligada a lo artificial: "El festín barroco

7 Se trata, por supuesto, del famoso poema de 1911 que comienza con la exhortación: "Tuércele el cuello al cisne de engañoso plumaje". 
nos parece, al contrario, con su repetición de volutas, de arabescos y máscaras, de confitados sombreros y espejeantes sedas, la apoteosis del artificio, la ironía e irrisión de la naturaleza, la mejor expresión que J. Rousset ha reconocido en la literatura de toda una 'edad': la artificialización"(180).

Perlongher cierra su ensayo con una paráfrasis de Sarduy ("barroco: perla irregular, nódulo de barro", 180), pero da la impresión de que se acerca a su predecesor para alejarse de él. En el argentino no parece haber una distinción tajante entre lo natural y lo artificial, o al menos ésta parece resolverse en su predilección por lo orgánico del barro frente a lo inorgánico de la perla o la piedra:

Si el barroco del Siglo de Oro, como dijimos, se monta sobre un suelo clásico, el neobarroco carece, ante la dispersión de los estilos contemporáneos, de un plano fijo donde implantar sus garras (...) En su expresión rioplatense, la poética neobarroca enfrenta una tradición literaria hostil, anclada en la pretensión de un realismo de profundidad que suele acabar chapoteando en las aguas lodosas del río. De ahí el apelativo paródico de neobarroso para denominar esa nueva emergencia. ("Neobarroco y neobarroso" 30)

\section{Cadáveres}

En una entrevista con Daniel Freidemberg y Daniel Samoilovich, Néstor Perlongher declara: "En este sentido, yo una vez pensé en una construcción que sería como una especie de 'barroco de trinchera', una especie de barroco cuerpo a tierra, o ligado a la tierra"(29). Pero la importancia del barro y lo terrestre está lejos de ser sólo una declaración programática en la poesía de Perlongher. Precisamente, una de las piezas centrales de su primer libro, Austria-Hungría, de 1980, se llama "El polvo". Respecto de este poema, Cecilia Palmeiro observa:

Ya el título deriva el sentido hacia por lo menos tres posibilidades: polvo como maquillaje, artificio femenil, máscara, simulacro; polvo como metáfora bíblica de la muerte (...) y finalmente, según el argot, como acto sexual, coito. De hecho, esos tres flujos de sentido conforman una máquina de guerra que articulada en el lenguaje dará como resultado la barrosidad de la escritura para formular un programa de una política sexual. (14)

Palmeiro ve muy bien lo que se juega en esa serie polvo/barro/tierra. Por un lado el afeite, la forma, el artificio. Por otro, la potencia sexual, generativa, de la materia orgánica. Por último, la muerte, la descomposición, el retorno a la tierra. A esto habría que agregar dos cosas. En primer lugar, la tierra opuesta al territorio como fuerza de desterritorialización que, en el caso de Perlongher, 
opera fundamentalmente sobre la lengua ${ }^{8}$ : por eso, no es ocioso su exilio en Brasil, ese verdadero Otro latinoamericano, y su portuñolización del castellano. En segundo lugar, y en estrecha relación con lo anterior, el barro como mezcla. Aquí también se verifica fundamentalmente en el plano lingüístico: de lenguas y registros, de lo alto con lo bajo, de lo oral con lo escrito, etc.

Esta articulación de los diversos sentidos de lo barroso, en la que lo vivo y lo muerto se reúnen bajo el signo de lo orgánico, se vuelve particularmente significativa a la luz de los desarrollos teóricos de Robert Pogue Harrison en The Dominion of the Dead. En el prefacio de este libro fundamental, Harrison se plantea: "To uncover what I call the humic foundations of our life worlds. A humic foundation is one whose contents have been buried so that they may be reclaimed by the future. The humic holds in its conserving element the unfinished story of what has come to pass" (10).Esos fundamentos húmicos son, para Harrison, el fundamento de lo humano.

Para esto se apoya en Vico, que encuentra en la etimología latina de $h u$ manitas el verbo humare, enterrar. Entonces, ser humano, dirá Harrison, es una forma de relacionarse con los muertos y de enterrar. Y sin embargo la muerte no se opone a la vida. En apoyo de este argumento, Harrison cita a Nietzsche: "Nietzsche once declared: 'Let us beware of saying that death is opposed to life. The living is merely a type of what is dead, and a very rare type' (Gay Science [109], 168)" (1). Y a continuación concluye: "Because the earth has reabsorbed the dead into its elements for so many millions upon millions of years, who can any longer tell the difference between receptacle and contents?" (2).

A este respecto, hay en Perlongher una obsesión por los cadáveres que se liga con las teorías de Harrison en el sentido en que lo vivo y lo muerto entran en una zona de contigüidad que a menudo los vuelve indistinguibles. Pero esta obsesión no opera únicamente en el plano formal, como hemos desarrollado hasta ahora. También aparecen y reaparecen poemas sobre los cadáveres patrios en los que éstos, por lo general, no acaban de morir y viven una entrevida de algún tipo, o no terminan de desaparecer. Además de los desaparecidos de la dictadura, Perlongher le dedica tres textos al cuerpo (no) muerto de Eva Perón: los poemas "El cadáver" y "El cadáver de la nación", y la prosa "Evita vive". Estos textos son muy diferentes entre sí. El primero es un poema extrañamente poco neobarroso, por la

8 Pero también a nivel de lo telúrico en tanto cultura nacional: "[M]e parece que en el caso de Argentina hay que destruir esa pacatería solemne, anclada en cosas históricas, tradicionales", le dice Perlongher a Eduardo Milán respecto de la gauchesca. Milán, Eduardo, "El neobarroco rioplatense", en faque, nro. 134, Montevideo, 3 de agosto de 1986. 
claridad referencial, donde una primera persona, en diálogo con una segunda que permanece en silencio, se empeña en memorializar el cadáver de Eva antes de que empiece a descomponerse, pero también a "desvanecerse": a desaparecer, según la historia espeluznante del cadáver robado.

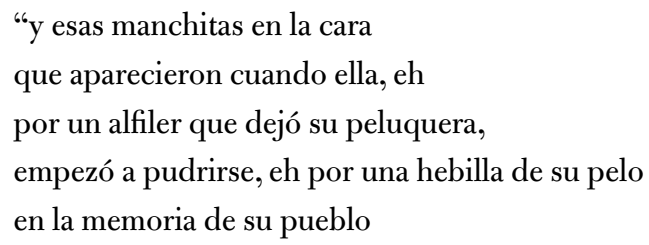

Y si ella

se empezara a desvanecer, digamos"

El segundo escenifica un ritual haitiano de zombificación, como contrapartida del embalsamamiento del cadáver o, más precisamente, de la preparación previa del cuerpo por parte de su peluquero. "Evita vive" está compuesto por tres viñetas narrativas: en cada una de ellas, Evita vuelve lumpenizada de la muerte como benefactora ya no sólo de los humildes sino también de los marginados por la propia retórica peronista: prostitutas y marineros africanos, junkies y michés. Aquí, a diferencia del carácter espectral que la crítica suele atribuirle al cadáver de Eva, creemos que más bien la suya es una aparición zombi, puesto que, una vez más, el énfasis está puesto en su corporeidad: el pelo, las uñas verdes, las manchas del cáncer. Además, el relato, a causa de la falta de continuidad entre las viñetas, pone en escena una multiplicidad de Evas. Como es sabido, el zombi siempre es multitud, y estas apariciones múltiples parecieran sugerir una Buenos Aires invadida por un ejército de Evas que regresan de la muerte, jugando, además, en clave zombi, con la conocida frase -falsamente atribuida a Evita- "volveré y seré millones".

Como observó el poeta mexicano Luis Felipe Fabre, "a lo largo de su obra, Perlongher insiste en el cabello" (14). Y, precisamente, el hilo conductor entre estos textos tan disímiles, que también los vincula con "Cadáveres", es la mención casi obsesiva del pelo de la muerta, especialmente su característico rodete. Es sabido que, al igual que las uñas, de aparición también recurrente en la escritura de Perlongher, el cabello sigue creciendo después de la muerte, de modo que estos elementos ponen en evidencia este umbral de cohabitación entre lo vivo y lo muerto, entre lo orgánico y lo inorgánico.

En este sentido, "El cadáver de la nación" es un ejemplo paradigmático. El poema parece narrar un rito vudú llevado a cabo con el cuerpo de Eva (sección 1), la exhibición de su cadáver embalsamado en la CGT (2), una conversación de Eva 
con su peluquero donde parece darle instrucciones previas a su muerte (3), y un monólogo del propio peluquero (4). "El cadáver de la nación" pasa de abundar en referencias textiles en las primeras dos secciones para volcarse completamente a lo capilar en la tercera, donde Evita habla con su peluquero: "Aranda hágame los rulos con la delicadeza de una onda cetrina nívea en su rubor amar el illo el bigudí sujéteme con un papelito disimulado en la tintura de la entretela para erguir el mamotreto del rodete hasta una altura suficiente para espantar las engrupidas junto a mi lecho que no digan que se me bajó el copete siquiera yerta" (16). Al final, en la cuarta, como hemos dicho, directamente emerge la voz del peluquero. Pero como el texto está dislocado cronológicamente, no se sabe si en efecto se trataba de instrucciones previas a la muerte o las palabras de una evita zombie.

En cualquier caso, en este pasaje puede verse una transición del artificio inorgánico -el drapeado, la tela- al orgánico -el pelo y el rodete- que pone en abismo, por un lado, la zombificación que se relata en el poema y, a nivel metapoético, la predilección por una de las dos polaridades neobarrocas que Perlongher había esbozado en "Caribe transplatino": el tajo frente al tatuaje. Este último, asociado a la poética de Sarduy, pondría en primer plano esa cualidad "de superficie" del barroco, mientras que el primero estaría "más ligado a la ilusión rioplatense por el sentido, por la profundidad" (Chitarroni 23). A propósito del tajo, el ejemplo más típico sería "El niño proletario" de Osvaldo Lamborghini, otro texto violentamente político, y otra invectiva contra el realismo socialista que reescribe además la historia de otro de los cadáveres fundantes de la literatura argentina. Allí se nos ofrece una transfiguración de la muerte del unitario de "El matadero", de Esteban Echeverría, que Lamborghini invierte al sustituir al aristócrata letrado, que no hace sino hablar, por un chico de clase baja que se mantiene en silencio, y condensa con otro episodio del relato de Echeverría, la muerte del niño degollado por el lazo del que se desata un toro en su huida.

En términos generales, sin embargo, Perlongher nunca se decanta por completo por ninguno de estos polos, sino que oscila entre ambos, y es precisamente este espacio intermedio donde su poética se hace efectiva y cobra mayor productividad política. "Cadáveres", su poema más conocido, comparte con "El niño proletario" la voluntad de desmarcarse de la poesía social: "Cadáveres' podría incluirse en un grupo de textos que dijeran algo sobre la guerra sucia, pero no creo que estuviera muy cómodo entre esos textos. Yo no voy a asumir esa postura del poeta social. Hay siempre que irse para el otro lado, tender líneas de fuga" (Chitarroni 24).

La misma circunstancia de escritura del poema tiene que ver con una línea de fuga. Perlongher escribió "Cadáveres" en 1982, en un momento en que los 
muertos de la dictadura comenzaban a aparecer por todas partes, a bordo de un ómnibus rumbo a San Pablo. El poema parece replicar este alejamiento, y comienza con una descripción de un descampado, límite entre el campo y la ciudad, la civilización y la barbarie que recuerda la muerte del unitario de "El matadero":
Bajo las matas
En los pajonales
Sobre los puentes
En los canales
Hay Cadáveres

Esta sensación de inevitabilidad se ve enfatizada por la rima, un elemento poco usado por Perlongher. La segunda estrofa, por lo demás, en la reunión de alusiones portuarias y ferroviarias, parece aludir a la terminal de ómnibus de Retiro, desde donde Perlongher emprendió su regreso a Brasil. Pero allí acaban casi por completo las localizaciones geográficas: la referencialidad del poema empieza a enloquecer y los cadáveres pasan a encarnarse literalmente en cualquier parte. Por este magma lírico desfila una larga galería de mujeres infames, en el sentido de Foucault: profesoras, costureras, manicuras, abuelas, yernas y matronas casadas, todas igualadas en una naturaleza deseante que va desde el guiño modernista hasta la explicitud más absoluta. Como afirma Jorge Panesi, la lengua deviene "loca", tanto en sentido clínico como en términos de identidad de género: como desquiciamiento y como performance menor y artificializada de lo femenino. Pero como el mismo Panesi nota: "La regularidad de los versos, su recursividad regulada parece lo contrario de la locura, pero justamente los esquemas de la razón esconden monstruos. Cuando una lengua se vuelve loca deja salir a los monstruos, los desata, los desvela" (5).

La regularidad alucinada de los heptasílabos y los endecasílabos, antiguos componentes de la silva gongorina, no sólo evita la disgregación formal del poema sino que en su potencia arrolladora, conduce la carga libidinal de esa lengua enloquecida. En este contraste entre forma recurrente y contenido desatado está el "poner el cuerpo" del que hablaba Palmeiro: extremar la materialidad libidinal del lenguaje poético, cargar la lengua con una proliferación delirante de imágenes sensoriales, enhebradas sin embargo por un latido rítmico que impide su desintegración.

"Cadáveres" lleva este poner el cuerpo hasta su límite, precisamente porque todo el tiempo se nos está recordando la ausencia de los cuerpos. Además, ¿cómo poner el cuerpo cuando se trata de cuerpos que "no están ni vivos ni muertos, 
están desaparecidos", en palabras del dictador Jorge Rafael Videla? La operación que lleva a cabo el poema es trasladar esa materia ausente de los cuerpos de los desaparecidos a la materialidad de un lenguaje erotizado. En ese "devenir loca", la lengua yira, merodea lascivamente en torno a lo que falta, y al señalar esa ausencia la vuelve presente, tanto en términos de entidad como históricos, en el sentido en que permite memorializar aquello que se ha visto privado incluso de su derecho a ser recordado: lo devuelve a una entrevida cuya cifra es el "en" anafórico que el poema repite sin cesar.

Pero a la vez, como hemos visto, esta lengua poética neobarrosa está hecha exclusivamente de restos, sedimentos y desechos. Es, en efecto, un "fundamento húmico" (73), en el sentido de Robert Pogue Harrison, donde se mezclan lo orgánico y lo inorgánico, y lo vivo y lo muerto se vuelven indistinguibles. $\mathrm{Y}$ en este devolver, la vida, la presencia y el presente mediante una lengua cuya vitalidad incontenible radica en su aprovechamiento del equivalente lírico de la materia cadavérica está el gesto político de Perlongher, doblemente efectivo al esquivar tanto la poesía social como la mera aprehensión del Zeitgeist para atacar a través de la forma.

Y este gesto político de la máquina barroca deviene biopolítico al tener como blanco de su ataque la tanatopolítica del proceso militar. Porque precisamente el programa de la dictadura, mediante la desaparición de los cadáveres de sus víctimas, convertidas por consiguiente en zoé, vida desnuda, consistió en disolver el "pacto sepulcral" que, en términos de Harrison, liga al cadáver con la comunidad al permitir que se inscriba su recuerdo. Dice Gabriel Giorgi respecto de los cadáveres cuya memorialización el biopoder se ocupa de impedir:

[L] a no-persona, la vida no personal, en cambio, aquella cuya muerte es insignificante para una comunidad, y que no cuenta para la memoria compartida; allí donde el cadáver entra en intersección con, por un lado, el mundo de los animales (en contigüidad con lo animal, lo orgánico, lo meramente biológico) y por otro con el dominio de lo inorgánico, el cuerpo cosa, el cuerpo vuelto objeto y fósil.

A la tanatopolítica del proceso, Perlongher le opone una poética de los restos: inorgánicos, como la "perla irregular", u orgánicos como el "nódulo de barro", distinción que en Sarduy parecía inclinarse por la artificialidad de lo inorgánico. En Perlongher, sin embargo, en el vaivén que nunca se resuelve entre uno y otro polo se crea un suelo -barroso e inestable pero suelo al fin-del que florece una necropoética que opera políticamente removiendo los sedimentos de la cultura y poniéndolos en el mismo plano, produciendo a la vez una dislocación formal y temporal. 
Esta necropoética debe ser entendida en los términos en que Ovidio representaba el mito de Orfeo. Ciertamente, en el oxímoron de su etimología -nekrós es cadáver y póiesis, creación- vuelven a resonar esa voz muerta y esa lira incorpórea, en todo su carácter productivo. La lírica está muerta, pero para Perlongher, tal vez en consonancia con la dimensión mística que su poesía adoptaría más tarde, es un gólem hecho de esa misma tierra, con su multiplicidad delirante de restos y sedimentos, cuya naturaleza a la vez orgánica e inorgánica asegura su fertilidad.

\section{Obras citadas}

Chitarroni, Luis. "Un uso bélico del barroco áureo". La papirola 1988. 23-24.

Girondo, Oliverio. En la masmédula. Buenos Aires: Losada, 1968. 349.

Kamenszain, Tamara. "Epílogo". Medusario. México D.F.:

Fondo de Cultura Económica, 1996. 487-488.

Esposito, Roberto. "Inmunidad, comunidad, biopolítica".

Las torres de Lucca enero-junio de 2012. 101-114.

Fabre, Luis Felipe. "No hay palábras: 'Hay cadáveres"'. Leyendo agujeros. Ensayos sobre (des)escritura, antiescritura y no escritura.

México D.F.: Fondo Editorial Tierra Adentro, 2005.

Freidemberg, Daniel y Daniel Samoilovich. "El barroco cuerpo a tierra". Diario de Poesía nro. 22, otoño de 1922. 29.

Giorgi, Gabriel. Formas comunes: animalidad, cultura, biopolítica. Buenos Aires: Eterna Cadencia, 2014.

González Martínez, Enrique. Tuércele el cuello al cisne en Poesía modernista: una antología general. México, DF: SEP/ UNAM, 1982.

Harrison, Robert Pogue. The Dominion of the Dead. Chicago:

The University of Chicago Press, 2003. $\mathrm{x}$.

Lamborghini, Osvaldo. "El niño proletario". Novelas y cuentos. Edición al cuidado de César Aira. Buenos Aires: Del Serbal, 1988. 63-69.

Milán, Eduardo. "El neobarroco rioplatense". Faque (1986, 3 de agosto). 33-39.

Ovidio. Metamorphoses. Hugo Magnus (ed). Gotha: Friedrich Andres Perthes, 1892.

Palmeiro, Cecilia. "Locas, milicos y fusiles: Néstor Perlongher y la última dictadura argentina". Estudios Vol. XIX, No. 38 (Julio-Diciembre 2011): 9-25.

Panesi, Jorge. "Cosa de locas: las lenguas de Néstor Perlongher".

Cuadernos LIRICO 2013. Web. 11 de mar. de 2014.

Perlongher, Néstor. "El cadáver". Austria-Hungría.

Buenos Aires: Tierra Baldía, 1980. 42-45. 
-. "Neobarroco y neobarroso". Medusario. México D.F.:

Fondo de Cultura Económica, 1996.

Prieto, Martín. Breve historia de la literatura argentina. Buenos Aires: Taurus, 2006.

Porrúa, Ana. "Cosas que se están hablando: versiones sobre el neobarroco". Boletín No.

13/ 14 (Centro de Estudios de Teoría y Crítica Literaria, diciembre 2007-abril 2008).

Sarduy, Severo. "El barroco y el neobarroco". América Latina en su literatura.

Coord. César Fernández Moreno. México D.F.: Siglo XXI, 1976. 172-189.

Vallejo, César. Los heraldos negros. Buenos Aires: Losada, 1972.

-. Trilce. Buenos Aires: Losada, 1982. 